\title{
Midlife Work-Related Stress is Associated with Late-Life Gray Matter Volume Atrophy
}

\author{
Shireen Sindia ${ }^{\mathrm{a}, \mathrm{b}, \mathrm{c}, *}$, Ingemar Kåreholt ${ }^{\mathrm{a}, \mathrm{d}}$, Gabriela Spulber ${ }^{\mathrm{b}}$, Hilkka Soininen ${ }^{\mathrm{e}, \mathrm{f}}$, \\ Miia Kivipelto ${ }^{\mathrm{b}, \mathrm{c}, \mathrm{e}, \mathrm{g}, \mathrm{h}}$ and Alina Solomon ${ }^{\mathrm{a}, \mathrm{b}, \mathrm{e}, \mathrm{h}}$ \\ ${ }^{a}$ Aging Research Center, Karolinska Institutet and Stockholm University, Stockholm, Sweden \\ ${ }^{\mathrm{b}}$ Karolinska Institutet Center for Alzheimer Research, Stockholm, Sweden \\ ${ }^{\mathrm{c}}$ Neuroepidemiology and Ageing Research Unit, School of Public Health, Imperial College London, London, UK \\ ${ }^{\mathrm{d}}$ Institute of Gerontology, School of Health and Welfare, Jönköping University, Jönköping, Sweden \\ ${ }^{\mathrm{e}}$ Department of Neurology, Institute of Clinical Medicine, University of Eastern Finland, Kuopio, Finland \\ ${ }^{\mathrm{f}}$ Department of Neurology, University of Eastern Finland, and Kuopio University Hospital, Kuopio, Finland \\ ${ }^{\mathrm{g}}$ Department of Chronic Disease Prevention, National Institute for Health and Welfare, Helsinki, Finland \\ ${ }^{\mathrm{h}}$ Department of Geriatrics, Karolinska University Hospital, Stockholm, Sweden
}

Accepted 23 October 2017

\begin{abstract}
.
Background: Work-related stress has been associated with an increased dementia risk. However, less is known about the mechanisms that underlie these associations.

Objective: The goal is to examine associations between midlife work-related stress and late-life structural brain alterations. Methods: The Cardiovascular Risk Factors, Aging, and Dementia (CAIDE) study participants were randomly selected from independent population-based surveys (mean age 50) in Finland. MRI measurements included gray matter (GM) volume, white matter lesions (WML) and medial temporal atrophy (MTA) (1st re-examination, $n=102$ ); and GM volume, hippocampal volume, WML volume, cortical thickness, and MTA (2nd re-examination, $n=64)$. Work-related stress comprised a score from two questions administered in midlife.

Results: Higher levels of midlife work-related stress were associated with lower GM volume $(\beta=-0.077, p=0.033)$ at the first re-examination, even after adjusting for several confounders. No significant associations were found with MTA, WML, or MRI measurements at the second re-examination.

Conclusion: Previously shown associations of midlife work-related stress with dementia risk may be at least partly explained by associations with lower GM volume in late-life. The lack of associations at the second re-examination may indicate a critical time window for the effects of midlife work-related stress, and/or selective survival/participation.
\end{abstract}

Keywords: Cortical thickness, gray matter volume, hippocampal volume, medial temporal lobe atrophy, stress, white matter lesions

\section{INTRODUCTION}

Recent studies have suggested that chronic stress in midlife is associated with an increased risk for dementia and Alzheimer's disease [1, 2]. Stress may exert its negative impact through neurological and

\footnotetext{
${ }^{*}$ Correspondence to: Shireen Sindi, PhD, Karolinska Institute, Aging Research Center, Gävlegatan 16, 8th floor, 11330 Stockholm, Sweden. Tel.: +46735508703; E-mail: shireen.sindi@ki.se.
}

endocrine mechanisms, whereby chronic stress and dysregulations in stress hormones are associated with reductions in gray matter (GM) volume and hippocampal volume, reduced total brain volume and increased MRI infarcts [3-5]. Chronic stress may also increase dementia risk through its association with the well established vascular and metabolic risk factors for dementia, including hypertension, type 2 diabetes mellitus and metabolic syndrome $[6,7]$. 
Few studies have investigated the associations between chronic stress and white matter lesions (WML) in older populations, and findings have been mixed. One study, using data from the Prospective Population Study of Women in Gothenburg, demonstrated that chronic stress in midlife was associated with more severe visually rated WML later in life among a population-based sample of women [8]. Yet, two other studies, the Pittsburgh Healthy Women Study and the Chicago Health and Aging Project, did not find similar associations with visually rated WML or WML volume [3, 9]. It is currently unclear whether the associations reported in the Prospective Population Study of Women in Gothenburg are also present among men, and whether they apply to workrelated stress, which is a specific source of chronic stress. To the best of our knowledge, no studies have reported on the associations between midlife workrelated stress and visually rated medial temporal lobe atrophy (MTA) or cortical thickness later in life.

We have recently reported significant associations between midlife work-related stress and increased risk for mild cognitive impairment, dementia, and Alzheimer's disease in late-life [10]. Considering these findings, it is important to investigate the potential underlying mechanisms. In addition, while the impact of generalized chronic stress on neuroimaging measures has been previously investigated, it is still unclear to what extent such associations apply to midlife work-related stress as a specific source of chronic stress. The goal of the present study is to assess whether midlife work-related stress is associated with structural brain alterations on MRI later in life.

\section{MATERIALS AND METHODS}

\section{CAIDE study design}

The current study included 102 participants in the Cardiovascular Risk Factors, Aging and Dementia (CAIDE) population-based study with MRI scans at the first late-life CAIDE re-examination, and a different group of 64 participants with MRI scans at the second late-life re-examination who also had data on midlife work-related stress. The CAIDE study and CAIDE participants with MRI scans have previously been described in detail [11]. CAIDE participants were first examined in midlife within the North Karelia Project and the Finnish part of Monitoring Trends and Determinants in Cardiovascular Disease (FINMONICA) study (one midlife examination in 1972,
1977, 1982, or 1987) [12]. In 1998, a random sample of 2,000 individuals who were still alive, aged 65-79 years, and living in the cities of Kuopio and Joensuu were invited for a first late-life re-examination. A total of 1,449 (72.5\%) individuals participated. Participants returned for a second late-life re-examination between 2005 and 2008. Of the initial 2,000 sample, 1,426 were still alive and living in the same region in 2005, and $909(63.7 \%)$ came to the reexamination. The CAIDE study was approved by local ethics committees of Kuopio University Hospital. Written informed consent was obtained from all individual participants included in the study. The study complies with the Declaration of Helsinki.

At both re-examinations, cognitive performance was assessed using a three-step protocol for dementia diagnosis: screening phase, clinical phase and differential diagnostic phase. At the first re-examination (1998), participants who scored $\leq 24$ on the MiniMental State Examination (MMSE) at screening were referred for further examinations. At the second re-examination (2005-2008), participants with $\leq 24$ points on MMSE, or with a decrease $\geq 3$ points on MMSE since 1998, or with $<70 \%$ delayed recall in the CERAD word list (The Consortium to Establish a Registry for Alzheimer's disease [CERAD]), or with informant concerns regarding the participant's cognition were referred for further examinations. These additional criteria were used to increase sensitivity and detect milder cognitive impairment. The clinical phase involved comprehensive neurological, cardiovascular and neuropsychological examinations. The differential diagnostic phase included brain imaging (MRI/CT), blood tests, and cerebrospinal fluid (CSF) analysis if needed, and electrocardiogram. A review board consisting of the physician, neuropsychologist and a senior neurologist ascertained the primary diagnosis based on all information. Dementia was diagnosed using the Diagnostic and Statistical Manual of Mental Disorders (DSM-IV) criteria [13]. Mild cognitive impairment (MCI) was assessed using a modified version of the Mayo Clinic Alzheimer's Disease Research Center criteria [14].

\section{The CAIDE MRI populations}

Formation of the CAIDE MRI populations is shown in Fig. 1. At the first CAIDE re-examination, MRI was obtained from participants in the Kuopio cohort, using a case-control approach: 39 with dementia, 31 gender- and age- ( \pm 3 years) matched 


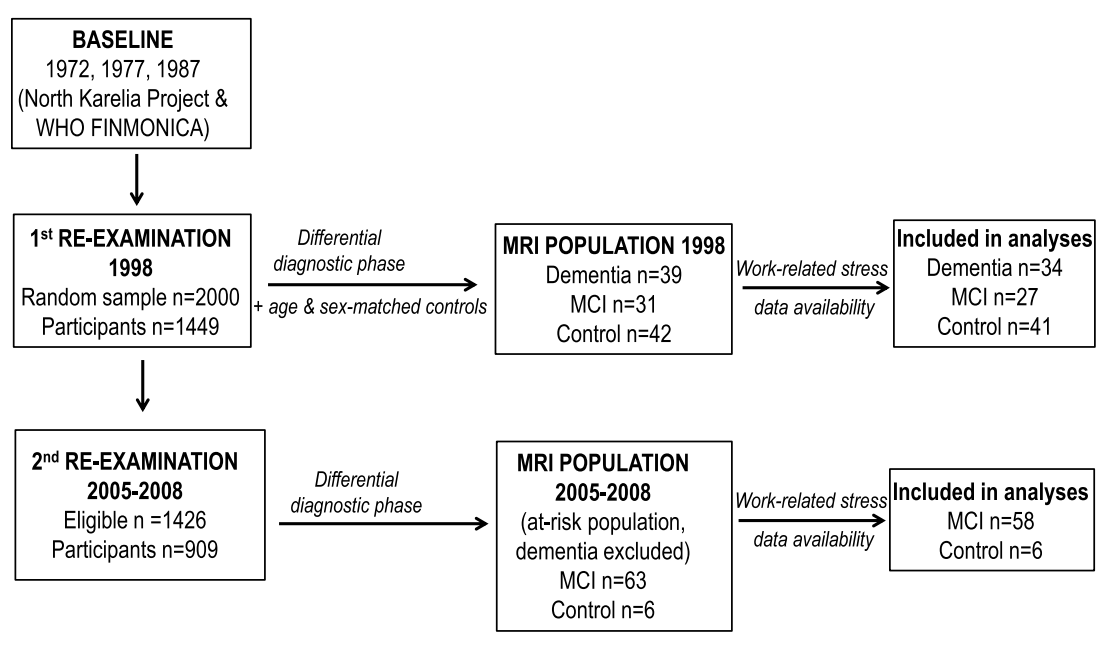

Fig. 1. Formation of the CAIDE MRI populations at the 1st and 2nd CAIDE re-examinations.

participants with MCI, and at least one similarly matched cognitively normal control $(n=42)$ for each dementia case (total 112 subjects, 102 with data on work-related stress).

At the second re-examination, MRI scans ( $n=113)$ were carried out only as part of the differential diagnostic phase for the Kuopio cohort, including only individuals with lower cognitive performance at screening (37 dementia, $70 \mathrm{MCI}$, and 6 cognitively normal controls). Due to the small number of controls, a case-control approach was not possible. The dementia cases were thus excluded from the current study, leaving a subsample of 64 elderly at risk for dementia with work-related stress data and MRI of adequate quality for brain volume measurements. Mean follow-up time from midlife was 21.5 years until the first re-examination, and 28 years until the second re-examination.

\section{MRI acquisition and image analysis}

The T1-weighted images were acquired using a three-dimensional magnetization prepared rapid acquisition gradient echo (3DMPRAGE) sequence on 1.5T MR scanners. One MRI scanner was used in the first re-examination (Siemens Magnetom Vision), while two scanners were used in the second re-examination (Siemens Magnetom Vision or Siemens Avanto). Axial fluid-attenuated inversion recovery images (FLAIR) were available from both re-examinations (parameters previously described in [15-17]. All images were visually checked by an experienced neuroradiologist to confirm that they were free of artefacts and clinically significant brain conditions such as tumors, major post-stroke lesions or normal pressure hydrocephalus.

In the first re-examination, WML were assessed from FLAIR images using a semi-quantitative visual rating scale [18] by a single rater blinded to clinical data. Lesions were rated separately from zero to three for five brain regions (frontal, parieto-occipital, temporal, infratentorial and basal ganglia) in both hemispheres. A single rater graded MTA from zero (no atrophy) to four (end-stage atrophy) bilaterally from $\mathrm{T} 1$-weighted images according to a visual rating scale commonly used in clinical practice [19]. MRIs were oriented perpendicular to the anterior commisure - posterior commisure line and MTA was rated from single coronal slice at the level where hippocampus, cerebral peduncles and pons were all visible. Total GM volume was measured using FSL FAST (FMRIB's Automated Segmentation Tool) [20] as previously described [11]. Total GM volume was normalized to the total intracranial volume (TIV) to correct for head size.

In the second re-examination, regional cortical thickness and volumes were assessed using the FreeSurfer software package, version 5.0 (http:// surfer.nmr.mgh.harvard.edu/) $[21,22]$. Total GM volume and hippocampal volume were normalized to TIV to correct for head size. Alzheimer's diseasesignature cortical thickness was calculated as the average cortical thickness for the following regions: entorhinal, inferior temporal, middle temporal, and fusiform [23]. WML volume was calculated using CASCADE, an automatic pipeline developed at Karolinska Institute, Stockholm, Sweden [24, 25]. T1 and FLAIR images were used as input for the 
image analysis. Pre-processing steps included affine registration with FLAIR as reference image, brain extraction, brain tissues segmentation and histogram matching for both sequences. WML were segmented using a cascade schema in which non-WML voxels (i.e., normal brain tissue) were trimmed away. Each level consisted of a separate classifier tailored to trim normal brain patterns. The last level consisted of morphological and spatial filtering. The cascade schema was followed by boundaries refining and the final output consisted of volumes and masks of the WML. Visual MTA assessment was conducted identically to the first re-examination.

\section{Assessment of midlife work-related stress}

Perceived work-related stress was measured in midlife using two 5-point Likert scale questions focusing on 'job demands', previously validated [26] and used reliably in several studies (for details see [10]. The questions were "How often do you struggle to cope with the amount of work?" and "How often are you bothered by constant hurry at work?". Response options were: $0=$ never, $1=$ rarely, $2=$ sometimes, $3=$ often, and $4=$ always. Responses to the two questions were highly correlated $(\mathrm{r}=0.622$, $p=0.0001)$ and the original scores were summed to produce a composite measure of work-related stress ( 0 to 8 points, with higher score indicating higher levels of stress).

\section{Other assessments}

At baseline (midlife), assessments and survey methods were standardised and adhered to international guidelines and the WHO MONICA protocol [27]. Re-examination surveys were similar and comparable to those at baseline. Baseline surveys involved self-administered questionnaires on medical history, sociodemographic factors, health status, health-related behaviours and psychological-related factors, including hopelessness assessed with two previously described 5-point Likert scale questions [10]. Main lifetime occupation was assessed by asking individuals to select their longest-held occupation among the following categories: office/service, farming/forestry, mining/industrial/construction work, housewives, or other. Occupation type was then categorized as office/service (white collar versus blue collar jobs) compared to all others. A trained nurse verified the answers. Information on midlife history of respiratory and cardio/cerebrovascular conditions (chronic obstructive pulmonary disease, asthma, coronary artery disease, stroke, myocardial infarction, atrial fibrillation, cardiovascular surgery, heart failure or diabetes) was obtained from the national Hospital Discharge Register. APOE genotype was assessed from blood leucocytes using polymerase chain reaction and HhaI digestion [28].

\section{Statistical analyses}

Analyses were carried out using Stata software version 14 (Stata Corp, College Station, TX, USA). Descriptive statistics for population characteristics were analyzed using cross-tabulation and $\chi^{2}$ for categorical variables and independent samples $t$-test for continuous variables. The level of significance was set to $p<0.05$ in all analyses.

\section{MRI outcomes in the first re-examination}

Zero-skewness log-transformations were applied to the total WML visual rating score and TIV-adjusted total GM volume (Stata command lnskew0) to create variables with zero skewness. Linear regressions were carried out to assess the associations between these MRI measures and midlife work-related stress. The sum of left and right visual MTA ratings was calculated, and MTA was categorized as $0-1$ points $(n=24), 2$ points $(n=45), 3-5$ points $(n=22)$. Ordinal logistic regression was used to analyse associations between midlife work-related stress and MTA. All results are presented as $\beta$ coefficients ( $p$-values). To ensure representativeness of the 1998 MRI population, data in all analyses were weighted for the inverse probability of each person from the original CAIDE population to be included in the 1998 MRI population.

\section{MRI outcomes in the second re-examination}

Zero-skewness log-transformations were applied to the TIV-adjusted total GM volume, WML volume, TIV-adjusted hippocampal volume and Alzheimer's disease-signature cortical thickness. Linear regressions were carried out to assess the associations between these MRI measures and midlife workrelated stress. MTA was categorized as $0-2$ points $(n=47), 3$ points $(n=9)$, and $4-6$ points $(n=13)$; cutoffs were increased in order to achieve more balanced group sizes, since MTA was higher at the second reexamination. Ordinal logistic regression was used to analyse associations between midlife work-related stress and MTA. All results are presented as $\beta$ coefficients ( $p$-values). 
All analyses were adjusted for age, sex, education, follow-up time, and APOE genotype $(\varepsilon 4$ carrier/non-carrier) (Model 1). Model 2 was additionally adjusted for type of occupation (white collar versus blue collar jobs) and midlife hopelessness. Model 3 was Model 1 additionally adjusted for midlife cardio/cerebrovascular conditions. Because two different MRI scanners were used at the second re-examination, all second re-examination analyses were also adjusted for scanner type.

\section{RESULTS}

Clinical and sociodemographic characteristics of the two MRI populations in the first and second re-examination are presented in Table 1 . The 1998 MRI population did not differ significantly from the rest of CAIDE participants regarding midlife age, work-related stress, midlife cardio/cerebrovascular/ respiratory conditions, and proportion of APOE $\varepsilon 4$ carriers and women (all $p>0.05$, data not shown); however, they had lower levels of education
( $p=0.017)$, were more likely to have non-white collar jobs in midlife $(p=0.035)$, and higher midlife levels of hopelessness $(p=0.010)$. The 2005-2008 MRI population did not differ significantly from the rest of CAIDE participants regarding midlife age, work-related stress, occupation type, midlife cardio/cerebrovascular/respiratory conditions, hopelessness, and proportion of APOE $\varepsilon 4$ carriers and women (all $p>0.05$, data not shown); however, they had lower levels of education $(p=0.042)$.

Associations between midlife work-related stress and late-life MRI measurements are shown in Table 2. Higher levels of work-related stress in midlife were significantly associated with lower GM volume at the first re-examination (Model $1 \beta$-coefficient $=-0.091$, $p=0.047$; Model $2 \beta$-coefficient $=-0.077, p=0.033$ ). This association was attenuated after adjusting for cardio/cerebrovascular/respiratory conditions (Model $3 \beta$-coefficient $=-0.081, p=0.099$ ). No significant associations were found between midlife work-related stress and visually rated MTA or WML at the first re-examination.

Table 1

Characteristics of the CAIDE MRI populations in the 1st and 2nd re-examinations

\begin{tabular}{|c|c|c|c|c|}
\hline Characteristics & $n$ & $\begin{array}{l}\text { MRI population in } \\
1 \text { st re-examination }\end{array}$ & $n$ & $\begin{array}{l}\text { MRI population in } \\
\text { 2nd re-examination }\end{array}$ \\
\hline Age in midlife, years & 102 & $51.7(5.1)$ & 64 & $49.4(5.9)$ \\
\hline Age at re-examination, years & 102 & $73.2(3.8)$ & 64 & $77.8(3.5)$ \\
\hline Sex (men), n $(\%)$ & 102 & $36(35.3 \%)$ & 64 & $24(37.5)$ \\
\hline Education, years & 101 & $7.2(2.6)$ & 62 & $7.8(2.7)$ \\
\hline Total follow-up time, years & 102 & $21.5(3.2)$ & 64 & $28.4(4.5)$ \\
\hline APOE $\varepsilon 4$ status (carrier), n (\%) & 100 & $45(45.0 \%)$ & 54 & $22(40.7)$ \\
\hline $\begin{array}{l}\text { Any work-related stress in midlife, } \mathrm{n}(\%) \\
\text { (compared to no stress, score } 0 \text { ) }\end{array}$ & 102 & $91(89.2 \%)$ & 64 & $59(92.2 \%)$ \\
\hline $\begin{array}{l}\text { Midlife history of } \\
\text { cardio/cerebrovascular/respiratory } \\
\text { conditions, } \mathrm{n}(\%)\end{array}$ & 102 & $6(5.9 \%)$ & 64 & $4(6.3 \%)$ \\
\hline $\begin{array}{l}\text { Midlife occupation type (white versus blue } \\
\text { collar), } \mathrm{n}(\%)\end{array}$ & 93 & $30(32.3 \%)$ & 59 & $27(45.8 \%)$ \\
\hline $\begin{array}{l}\text { Midlife hopelessness (reported symptoms), } \mathrm{n} \\
(\%)\end{array}$ & 101 & $64(63.4 \%)$ & 63 & $32(50.8 \%)$ \\
\hline \multicolumn{5}{|l|}{ MRI measures in late-life* } \\
\hline Total intracranial volume & 82 & $1376.3(124.0)$ & 62 & $1542.9(180.4)$ \\
\hline Total GM volume & 82 & $498.9(49.1)$ & 62 & $510.8(61.1)$ \\
\hline WML (visually rated) & 102 & $6.1(4.2)$ & - & - \\
\hline WML volume & - & - & 64 & $32.6(28.4)$ \\
\hline MTA (visually rated) & 83 & $1.66(1.11)$ & 64 & $2.42(1.0)$ \\
\hline Hippocampal volume $\left(\mathrm{cm}^{3}\right)$ & - & - & 64 & $3.09(0.63)$ \\
\hline AD-signature cortical thickness, $\mathrm{mm}$ & - & - & 62 & $2.58(0.28)$ \\
\hline
\end{tabular}

Values are means (SD) for continuous variables unless otherwise specified. Data for the 1998 MRI population (first reexamination) are weighted for the inverse probability of each person from the original CAIDE population to be included in the 1998 MRI population. * Different automatic MRI analysis methods were used at the 1st and 2nd re-examinations (i.e. mean total intracranial volume and total gray matter volume show some differences). Factors related to image quality (e.g., acquisition parameters, scanners) were different between re-examinations, limiting image analysis in some cases (i.e., WML volume and cortical thickness could not be measured reliably at the 1 st re-examination). MRI populations at 1 st and 2 nd re-examinations include different individuals. 
Table 2

Midlife work-related stress and late-life MRI outcomes in the 1st and 2nd CAIDE re-examinations

\begin{tabular}{lrrr}
\hline & Model 1 & $\begin{array}{c}\text { Model 2 } \\
\beta \text { coefficients }(p \text {-values })\end{array}$ & \multicolumn{1}{c}{ Model 3 } \\
\hline 1st CAIDE re-examination & & & \\
$\quad$ Total GM volume & $\mathbf{- 0 . 0 9 1}(\mathbf{0 . 0 4 7})$ & $\mathbf{- 0 . 0 7 7}(\mathbf{0 . 0 3 3})$ & $-0.081(0.099)$ \\
WML (visually rated) & $0.022(0.294)$ & $0.028(0.176)$ & $0.022(0.295)$ \\
MTA (visually rated* & $-0.387(0.698)$ & $0.073(0.943)$ & $-0.156(0.883)$ \\
2nd CAIDE re-examination & & & \\
$\quad$ Total GM volume & $0.013(0.842)$ & $0.042(0.553)$ & $-0.013(0.853)$ \\
WML volume & $-0.003(0.971)$ & $-0.023(0.716)$ & $-0.033(0.651)$ \\
MTA (visually rated)* & $-0.105(0.591)$ & $-0.206(0.345)$ & $0.084(0.714)$ \\
Hippocampal volume & $0.096(0.225)$ & $0.110(0.226)$ & $0.056(0.488)$ \\
AD-signature cortical thickness & $0.029(0.710)$ & $0.043(0.625)$ & $0.026(0.756)$ \\
\hline
\end{tabular}

Values were unstandardized. Model 1 is adjusted for age, sex, education, follow-up time and APOE status. Model 2 is additionally adjusted for type of occupation and midlife hopelessness. Model 3 is Model 1 additionally adjusted for midlife cardio/cerebrovascular/respiratory conditions. All analyses for the second re-examination additionally adjusted for scanner type. ${ }^{*}$ Ordinal logistic regressions were performed.

Midlife work-related stress was not significantly associated with MTA, WML volume, total GM volume, hippocampal volume or Alzheimer's disease-signature cortical thickness at the second reexamination (Table 2).

\section{DISCUSSION}

This study found for the first time that higher levels of midlife work-related stress were associated with lower total GM volume approximately 21 years later. This association remained significant even after adjusting for multiple confounding factors, but was attenuated when midlife respiratory and cardio/cerebrovascular conditions were taken into account. Such chronic conditions may thus at least partly explain the link between midlife work-related stress and lower late-life GM volume. Chronic stress has been previously associated with e.g. cardiovascular conditions [29], which in turn have been related to reduced GM volume and structural brain changes [30-33].

Previous studies have shown that perceived chronic stress may lead to, e.g., lower total GM and hippocampal volume, [5] via elevated levels of stress hormones (glucocorticoids) [3-5]. Elevated glucocorticoid levels have been associated with proinflammatory cytokines [34], which were in turn related to reduced GM [35-37]. In addition, elevated glucocorticoid levels accelerated $\beta$-amyloid production and tau pathology, and decreased amyloid- $\beta$ degradation in mouse models of Alzheimer's disease [38-41]. The hippocampus is particularly vulnerable to the detrimental effects of chronic stress [42, 43], and also to Alzheimer's disease-related pathology.
However, we did not find any significant associations between work-related stress and visually rated MTA, hippocampal volume or Alzheimer's diseasesignature cortical thickness. This may be explained by the relatively small sample size with limited statistical power, or discrepancies between self-reported and physiological stress measures, but it may also reflect potential differences between the effects of chronic generalized stress versus specific, more confined sources of stress (i.e., work-related).

Interestingly, while midlife work-related stress was associated with lower total GM volume at the first late-life CAIDE re-examination, this association was not found after a longer time period (second CAIDE re-examination). These results are consistent with our previous findings of significant associations between midlife work-related stress and increased risk for mild cognitive impairment, dementia, and Alzheimer's disease only at the first CAIDE re-examination, but not at the second re-examination [10]. The timeor age-specific associations between midlife workrelated stress and GM volume may be due to selective mortality and selective participation. Individuals who were still alive up to 30 years after midlife, participated in the study and did not develop dementia during follow-up may represent a sub-group more resilient to the effects of midlife work-related stress. Midlife work-related stress may also have a 'critical time window' regarding its effects on brain structures and functioning, i.e., most of its impact may become manifest at younger ages ( $<75$ years).

The lack of associations between midlife workrelated stress and WML in the present study is in line with the Pittsburgh Healthy Women Study and the Chicago Health and Aging Project, where no associations were found between self-reported stress and 
WML $[3,9]$. However, these findings are inconsistent with results from the Prospective Population Study of Women in Gothenburg study, where midlife psychological distress was associated with more severe WML and cerebral atrophy [8]. These differences may be at least partly related to the use of CT scans in the Gothenburg study. In addition, different measures of stress were used: the Pittsburg and Chicago studies used the Perceived Stress Scale focusing on the past two weeks [3] or the past month [9]; the current CAIDE study focused specifically on workrelated stress; and the Gothenburg study measured stress regarding everyday circumstances [8].

The main strengths of the present study are the availability of midlife data, inclusion of both men and women, long follow-up time (up to three decades), and several MRI outcomes. However, several methodological limitations need to be discussed. As the MRI sample sizes were small, these findings need replication in larger samples. Changes in MRI measures over time could not be assessed because only 18 subjects were scanned at both re-examinations. Factors related to image quality (e.g., acquisition parameters and scanners) differed between re-examinations, leading to differences in assessments available for each time point. Also, MRI scans were not available at the midlife examination.

The CAIDE MRI populations included selected participants in the first or second re-examination. In the 1998 MRI population, data weighting was used to achieve representativeness for the original CAIDE sample. In the 2005-2008 MRI population, the 64 participants at risk for dementia were not significantly different from the rest of CAIDE participants, with the exception of lower education levels. Survival and non-participation bias may have led to an underestimation of associations between work-related stress and MRI measures, as individuals who died or did not participate in re-examinations had poorer health status and were more likely to have dementia compared to participants [44].

In conclusion, a relation between midlife workrelated stress and lower GM volume may at least partly explain the previously shown associations with dementia [10]. The link between midlife work-related stress and subsequently lower GM volume may be at least partly due to chronic conditions, e.g., cardio/cerebrovascular conditions. Both work-related stress and chronic health conditions are risk factors that can be monitored and managed / modified with lifestyle-related and other intervention strategies. Thus, individuals with elevated work-related stress in midlife represent an at-risk group that may benefit from interventions for preventing potentially detrimental structural brain changes, and ultimately dementia.

Interestingly, midlife work-related stress was not associated with dementia [10] or structural brain changes after a longer time period (nearly three decades later), suggesting a critical time window for the effects of midlife work-related stress, and/or selective survival/participation. Whether most of the detrimental impact of midlife work-related stress is indeed manifested at younger ages ( $<75$ years), and whether this impact is potentially different from generalized chronic stress, needs to be confirmed in long-term cohort studies with larger neuroimaging populations. However, the present study further emphasizes the importance of initiating preventive strategies early during the working life.

\section{ACKNOWLEDGMENTS}

The authors would like to thank the CAIDE participants for their time and their valuable contribution to the data of this study.

S. Sindi receives postdoctoral funding from the Fonds de la recherche en santé du Québec (FRSQ) (27139), including its renewal (31819). A. Solomon receives research funding from the Academy of Finland $(287490,294061)$ and ALF grants 20130507, 20150589. M. Kivipelto receives research support from the Academy of Finland (278457), the Swedish Research Council for Joint Program of Neurodegenerative Disorders - prevention (MIND-AD), Alzheimerfonden, Alzheimer's Research \& Prevention Foundation, Center for Innovative Medicine (CIMED) at Karolinska Institutet South Campus, AXA Research Fund. H, Knut and Alice Wallenberg Foundation (Sweden), Stiftelsen Stockholms sjukhem (Sweden), Konung Gustaf V:s och Drottning Victorias Frimurarstiftelse (Sweden). Soininen receives funding from EU 7th framework collaborative project grant (HATICE), Academy of Finland for Joint Program of Neurodegenerative Disorders prevention (MIND-AD), UEF Strategic funding for UEFBRAIN, and EVO/VTR funding from Kuopio University Hospital.

\section{CONFLICT OF INTEREST}

The authors have no conflict of interest to report. 


\section{REFERENCES}

[1] Johansson L, Guo XX, Waern M, Ostling S, Gustafson D, Bengtsson C, Skoog I (2010) Midlife psychological stress and risk of dementia: A 35-year longitudinal population study. Brain 133, 2217-2224.

[2] Johansson L, Guo X, Hallstrom T, Norton MC, Waern M, Ostling S, Bengtsson C, Skoog I (2013) Common psychosocial stressors in middle-aged women related to longstanding distress and increased risk of Alzheimer's disease: A 38-year longitudinal population study. BMJ Open 3, $\mathrm{e} 003142$.

[3] Gianaros PJ, Jennings JR, Sheu LK, Greer PJ, Kuller LH, Matthews KA (2007) Prospective reports of chronic life stress predict decreased grey matter volume in the hippocampus. Neuroimage 35, 795-803.

[4] Lupien SJ, de Leon M, de Santi S, Convit A, Tarshish C, Thakur M, McEwen BS, Hauger RL, Meaney MJ (1998) Cortisol levels during human aging predict hippocampal atrophy and memory deficits. Nat Neurosci $\mathbf{1}$, 69-73.

[5] Zimmerman ME, Ezzati A, Katz MJ, Lipton ML, Brickman AM, Sliwinski MJ, Lipton RB (2016) Perceived stress is differentially related to hippocampal subfield volumes among older adults. PLoS One 11, e0154530.

[6] Pouwer F, Kupper N, Adriaanse MC (2010) Does emotional stress cause type 2 diabetes mellitus? A review from the European Depression in Diabetes (EDID) Research Consortium. Discov Med 9, 112-118.

[7] Kivimäki M, Nyberg ST, Batty GD, Fransson EI, Heikkilä K, Alfredsson L, Bjorner JB, Borritz M, Burr H, Casini A, Clays E, De Bacquer D, Dragano N, Ferrie JE, Geuskens GA, Goldberg M, Hamer M, Hooftman WE, Houtman IL, Joensuu M, Jokela M, Kittel F, Knutsson A, Koskenvuo M, Koskinen A, Kouvonen A, Kumari M, Madsen IE, Marmot MG, Nielsen ML, Nordin M, Oksanen T, Pentti J, Rugulies R, Salo P, Siegrist J, Singh-Manoux A, Suominen SB, Väänänen A, Vahtera J, Virtanen $M$, Westerholm PJ, Westerlund H, Zins M, Steptoe A, Theorell T; IPD-Work Consortium (2012) Job strain as a risk factor for coronary heart disease: A collaborative meta-analysis of individual participant data. Lancet 380, 1491-1497.

[8] Johansson L, Skoog I, Gustafson DR, Olesen PJ, Waern M, Bengtsson C, Bjorkelund C, Pantoni L, Simoni M, Lissner L, Guo X (2012) Midlife psychological distress associated with late-life brain atrophy and white matter lesions: A 32year population study of women. Psychosom Med 74, 120125.

[9] Aggarwal NT, Clark CJ, Beck TL, Mendes de Leon CF, DeCarli C, Evans DA, Everson Rose SA (2014) Perceived stress is associated with subclinical cerebrovascular disease in older adults. Am J Geriatr Psychiatry 22, 53-62.

[10] Sindi S, Hagman G, Hakansson K, Kulmala J, Nilsen C, Kareholt I, Soininen H, Solomon A, Kivipelto M (2017) Midlife work-related stress increases dementia risk in later life: The CAIDE 30-Year Study. J Gerontol B Psychol Sci Soc Sci 72, 1044-1053.

[11] Vuorinen M, Spulber G, Damangir S, Niskanen E, Ngandu T, Soininen H, Kivipelto M, Solomon A (2015) Midlife CAIDE dementia risk score and dementia-related brain changes up to 30 years later on magnetic resonance imaging. J Alzheimers Dis 44, 93-101.

[12] Puska P (2010) From Framingham to North Karelia: From descriptive epidemiology to public health action. Prog Cardiovasc Dis 53, 15-20.
[13] American Psychiatric Association (1994) Diagnostic and Statistical Manual of Mental Disorders, American Psychiatric Association, Washington, DC.

[14] Petersen RC, Smith GE, Waring SC, Ivnik RJ, Kokmen E, Tangelos EG (1997) Aging, memory, and mild cognitive impairment. Int Psychogeriatr 9(Suppl 1), 65-69.

[15] Vuorinen M, Solomon A, Rovio S, Nieminen L, Kareholt I, Tuomilehto J, Soininen H, Kivipelto M (2011) Changes in vascular risk factors from midlife to late life and white matter lesions: A 20-year follow-up study. Dement Geriatr Cogn Disord 31, 119-125.

[16] Vuorinen M, Kareholt I, Julkunen V, Spulber G, Niskanen E, Paajanen T, Soininen H, Kivipelto M, Solomon A (2013) Changes in vascular factors 28 years from midlife and latelife cortical thickness. Neurobiol Aging 34, 100-109.

[17] Rovio S, Spulber G, Nieminen LJ, Niskanen E, Winblad B, Tuomilehto J, Nissinen A, Soininen H, Kivipelto M (2010) The effect of midlife physical activity on structural brain changes in the elderly. Neurobiol Aging 31, 1927-1936.

[18] Wahlund LO, Barkhof F, Fazekas F, Bronge L, Augustin M, Sjogren M, Wallin A, Ader H, Leys D, Pantoni L, Pasquier F, Erkinjuntti T, Scheltens P, European Task Force on AgeRelated White Matter C (2001) A new rating scale for agerelated white matter changes applicable to MRI and CT. Stroke 32, 1318-1322.

[19] Scheltens P, Leys D, Barkhof F, Huglo D, Weinstein HC, Vermersch P, Kuiper M, Steinling M, Wolters EC, Valk J (1992) Atrophy of medial temporal lobes on MRI in "probable" Alzheimer's disease and normal ageing: Diagnostic value and neuropsychological correlates. J Neurol Neurosurg Psychiatry 55, 967-972.

[20] Zhang Y, Brady M, Smith S (2001) Segmentation of brain MR images through a hidden Markov random field model and the expectation-maximization algorithm. IEEE Trans Med Imaging 20, 45-57.

[21] Fischl B, Salat DH, Busa E, Albert M, Dieterich M, Haselgrove C, van der Kouwe A, Killiany R, Kennedy D, Klaveness S, Montillo A, Makris N, Rosen B, Dale AM (2002) Whole brain segmentation: Automated labeling of neuroanatomical structures in the human brain. Neuron 33, 341-355.

[22] Fischl B, van der Kouwe A, Destrieux C, Halgren E, Segonne F, Salat DH, Busa E, Seidman LJ, Goldstein J, Kennedy D, Caviness V, Makris N, Rosen B, Dale AM (2004) Automatically parcellating the human cerebral cortex. Cereb Cortex 14, 11-22.

[23] Jack CR Jr, Wiste HJ, Weigand SD, Knopman DS, Mielke MM, Vemuri P, Lowe V, Senjem ML, Gunter JL, Reyes D, Machulda MM, Roberts R, Petersen RC (2015) Different definitions of neurodegeneration produce similar amyloid/neurodegeneration biomarker group findings. Brain 138, 3747-3759.

[24] Damangir S, Manzouri A, Oppedal K, Carlsson S, Firbank MJ, Sonnesyn H, Tysnes OB, O'Brien JT, Beyer MK, Westman E, Aarsland D, Wahlund LO, Spulber G (2012) Multispectral MRI segmentation of age related white matter changes using a cascade of support vector machines. J Neurol Sci 322, 211-216.

[25] Cascade: Reproducible Segmentation of White Matter Changes using Strict Statistical Definition. http://www.github.com/Damangir/Cascade.

[26] Karasek R, Baker D, Marxer F, Ahlbom A, Theorell T (1981) Job decision latitude, job demands, and cardiovascular disease: A prospective study of Swedish men. Am J Public Health 71, 694-705. 
[27] (1988) Geographical variation in the major risk factors of coronary heart disease in men and women aged 35-64 years. The WHO MONICA Project. World Health Stat Q 41, 115140.

[28] Tsukamoto K, Watanabe T, Matsushima T, Kinoshita M, Kato H, Hashimoto Y, Kurokawa K, Teramoto T (1993) Determination by PCR-RFLP of apo E genotype in a Japanese population. J Lab Clin Med 121, 598-602.

[29] Steptoe A, Kivimaki M (2012) Stress and cardiovascular disease. Nat Rev Cardiol 9, 360-370.

[30] Alosco ML, Hayes SM (2015) Structural brain alterations in heart failure: A review of the literature and implications for risk of Alzheimer's disease. Heart Fail Rev 20, 561-571.

[31] Srinivasa RN, Rossetti HC, Gupta MK, Rosenberg RN, Weiner MF, Peshock RM, McColl RW, Hynan LS, Lucarelli RT, King KS (2016) Cardiovascular risk factors associated with smaller brain volumes in regions identified as early predictors of cognitive decline. Radiology 278, 198-204.

[32] Launer LJ, Lewis CE, Schreiner PJ, Sidney S, Battapady H, Jacobs DR, Lim KO, D'Esposito M, Zhang Q, Reis J, Davatzikos C, Bryan RN (2015) Vascular factors and multiple measures of early brain health: CARDIA brain MRI study. PLoS One 10, e 0122138.

[33] Vuorinen M, Damangir S, Niskanen E, Miralbell J, Rusanen M, Spulber G, Soininen H, Kivipelto M, Solomon A (2014) Coronary heart disease and cortical thickness, gray matter and white matter lesion volumes on MRI. PLoS One 9, e109250.

[34] Robles TF, Glaser R, Kiecolt-Glaser JK (2005) Out of balance: A new look at chronic stress, depression, and immunity. Curr Dir Psychol Sci 14, 111-115.

[35] McAfoose J, Baune BT (2009) Evidence for a cytokine model of cognitive function. Neurosci Biobehav Rev 33, 355-366.
[36] McEwen BS, Gianaros PJ (2011) Stress- and allostasisinduced brain plasticity. Annu Rev Med 62, 431-445.

[37] Marsland AL, Gianaros PJ, Abramowitch SM, Manuck SB, Hariri AR (2008) Interleukin-6 covaries inversely with hippocampal grey matter volume in middle-aged adults. Biol Psychiatry 64, 484-490.

[38] Dong H, Csernansky JG (2009) Effects of stress and stress hormones on amyloid-beta protein and plaque deposition. J Alzheimers Dis 18, 459-469.

[39] Green KN, Billings LM, Roozendaal B, McGaugh JL, LaFerla FM (2006) Glucocorticoids increase amyloid-beta and tau pathology in a mouse model of Alzheimer's disease. J Neurosci 26, 9047-9056.

[40] Kang JE, Cirrito JR, Dong H, Csernansky JG, Holtzman DM (2007) Acute stress increases interstitial fluid amyloidbeta via corticotropin-releasing factor and neuronal activity. Proc Natl Acad Sci U S A 104, 10673-10678.

[41] Lee KW, Kim JB, Seo JS, Kim TK, Im JY, Baek IS, Kim KS, Lee JK, Han PL (2009) Behavioral stress accelerates plaque pathogenesis in the brain of $\mathrm{Tg} 2576$ mice via generation of metabolic oxidative stress. J Neurochem 108, 165-175.

[42] Herman JP, Ostrander MM, Mueller NK, Figueiredo $\mathrm{H}$ (2005) Limbic system mechanisms of stress regulation: Hypothalamo-pituitary-adrenocortical axis. Prog Neuropsychopharmacol Biol Psychiatry 29, 1201-1213.

[43] McEwen BS (2012) The ever-changing brain: Cellular and molecular mechanisms for the effects of stressful experiences. Dev Neurobiol 72, 878-890.

[44] Kivipelto M, Helkala EL, Laakso MP, Hanninen T, Hallikainen M, Alhainen K, Soininen H, Tuomilehto J, Nissinen A (2001) Midlife vascular risk factors and Alzheimer's disease in later life: Longitudinal, population based study. BMJ 322, 1447-1451. 